\title{
Dealing with the Sins of the Past and Work towards a Nature-Based Future: New Innovative Technologies for Sustainable Agriculture
}

\author{
Leonard Sonnenschein*1 and Etyang Tiberious Brian² \\ ${ }^{1}$ International Director of Agriculture, President, Conservation for the Oceans Foundation, USA \\ ${ }^{2}$ Founder eNSPIRE Africa, Nairobi Kenya
}

*Corresponding author: Leonard Sonnenschein, International Director of Agriculture, President, Conservation for the Oceans Foundation, Missouri 63102, USA.

Received Date: March 21, 2019

Published Date: April 09, 2019

\begin{abstract}
Many third world developing countries agricultural systems are on the verge of a collapse due to a number of failed schemes. The residues of pesticides, herbicides, fertilizers, and over-use of soil have led to an inability for production to reach optimized levels. The structures for financing and subsidizing the farmers are broken and have proved to be less effective and unsustainable. The effects of climate change have further marginalized productivity due to change in soil conditions and relative cropping equations. The effluents from the farm fields are toxifying streams and residues are being built up into oceanic areas in the form of new eutrophic zones. Further to these factors are the insufficiencies of education, marketing, transportation and the growing lack of nutritional value of the crops raised. To all of these crises there is a need to reinvent the agriculture system towards natural and organic sustainability - economically, environmentally, for food security and eco-safety.
\end{abstract}

Independent field trials using the food-safe nature-based products produced by Salvation Farming Solutions have shown seed and soil treatments led to over $250 \%$ increase in corn production compared to Control and $100 \%$ pest control by comparison. The control corn had 1.5 cobs per stalk with each cob having corn borer infestation with experimental group having 3.5 cobs per stalk with no pests present. Nutritional analyses showed g/100g percentage change of $400 \%, 374 \%$ and $257 \%$ for protein, carbs and fat respectively.

Overall the system allows for reduction in fertilizer by up to $80 \%$ while costs of production by $50 \%$ while doubling the crop yield hence with potential to quadruple the income of the farmer. This platform that is market ready from seed to finished product which will be easy to sell into the market with high penetration based on regional government, private sector and development partners' support.

Keywords: Food security; Nutritional analysis; Eutrophic zones; Independent field trials; nature based; Organic; Soil treatment; Seed treatment; Farmer cost savings; Good Agricultural Practices; Sustainable; Fertilizer; Maize; Corn; Climate change; Drought; Pesticide; Innovative technologies

\section{Introduction}

The Sustainable Maize Program using Salvation Farming Solutions products is an initiative aimed at building capacity in science, technology, and innovation to boost food security and socioeconomic development using nature-based food safe products.

This model study relates to incorporating new ways to use natural means to remediate toxic soils using safe natural organic products that use geologic chemical binding processes that increase soil organic carbon content, remove and bind the toxic chemicals which prevents adsorption by the plants or into the crop while also rendering the toxic chemicals inert.

Recent results of lab and field trials have proved the effectiveness of these processes as shown in Figures 1-5. The solutions derived from this research have been independently tested in the laboratory, greenhouse, experimental farms and in field trials to great success.

Inclusive and innovative financing (new loans) need to be given to move the farmers and other agricultural sectors into start-to- 
finish support systems along with residual supports aftermarket to fund next cropping season and thus establish a sustainable model [1] Supports need to include early evaluations for needs identifications, education programs, community supports and commodity pricing and logistics. Research has also indicated that cost savings with improved production model is achieved with widescale adoption when small fees are paid with trainings provided and offered community-wide [2,3]. There needs to be better checks and balances in place to assist farmers in being prepared for dealing with funding these new methods, to establish fair pricing and encourage the farmer to be involved in more regionalized cropping with appropriate extension field agent support.

It has been demonstrated that most chemical based forms of agricultural products used can be replaced with less expensive and non-toxic natural and organic products with same or better productivity results [4,5] especially under an extension services methodology at a community level with financial supports and crop guarantees [6]. It is theorized by having government, market, university, banking and NGO support for regional roll-outs that these successful compacts can take sustainable hold within the rapidly declining agriculture systems [7], community by community.

The nutrient density of the foods that we eat makes a big difference in terms of the actual adsorption of nutrients [8]. Nutrients in the food provide the highest degree of absorption of those active ingredients because of the natural state of the nutrients in the food compared to nutrients within a formulary compound as how much nutrients are actually adsorbed [9]. Malnutrition can occur because of not enough food to eat, but also is a consequence of not getting the nutrients to the body because the nutritional quality of what we are eating is not sufficient to supply the metabolic needs [10]. In some African countries the nutritional value of some crops as food is not much different than eating cardboard.

\section{Previous Studies}

Nutritional analyses done in December, 2017 by International Crops Research Institute for the Semi-Arid Tropics (ICRISAT) which is an international organization which conducts agricultural research for rural development and is chartered by UN and FAO showed g/100g percentage change of $400 \%, 374 \%$ and $257 \%$ for protein, carbs and fat respectively as shown in Table 1, similar high levels of nutritional density as a result of seed and soil treatments were recorded by Nestle-Purina Analytical Laboratories in St. Louis, Missouri in 2014.

Table 1: Nutritional Analysis done at ICRISAT in 2017

\begin{tabular}{|c|c|c|c|}
\hline Test & Control & Treated & \% Change \\
\hline Protein & 3.3 & 13.2 & +400 \\
\hline Carbs & 18.7 & 70 & +374 \\
\hline Fat. & 1.4 & 3.6 & +257 \\
\hline
\end{tabular}

\section{Pretreated and Untreated Sweet Corn Cob Niacin Comparison (PPM)}

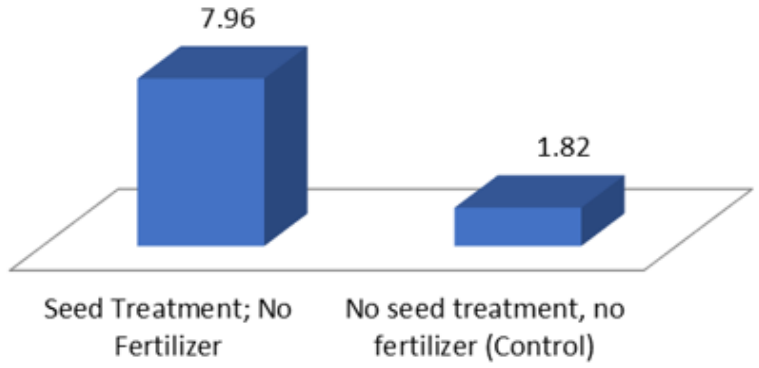

Figure 1: Over 400\% Increase in Niacin Content in the treated seed without fertilizer by Nestle Purina Analytical Laboratories [3].

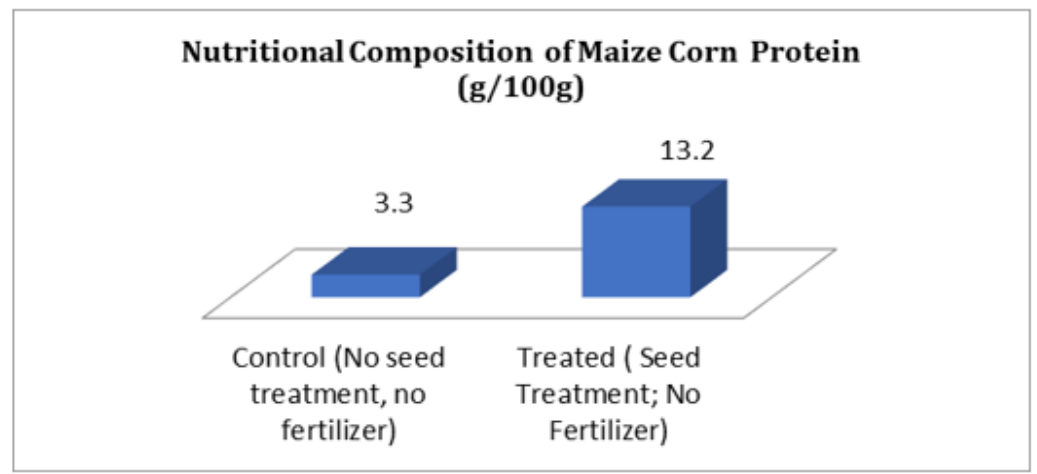

Figure 2: Nutritional Composition of Maize Corn [11] 
Previous Seed Pretreatment independent research has proved to offset lack of nutrition due to increased growth from $\mathrm{CO}_{2}$ abundance to improve nutritional density of crops including: $400 \%$ vitamin (niacin) increase (Figure 1), significant increase in Protein
(Figure 2), Carbohydrates (Figure 3), Fat (Figure 4) and along with significant overall production increases (Figure 5). Additionally, seed pretreatment has shown effectiveness in preventing pest infestations.

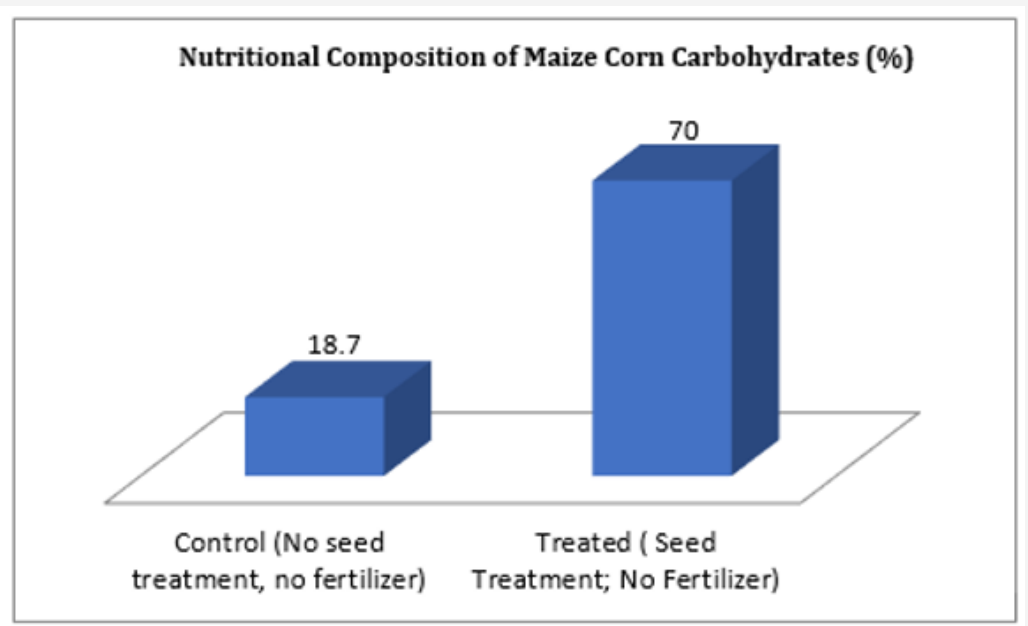

Figure 3: Nutritional Composition of Maize Corn [11]

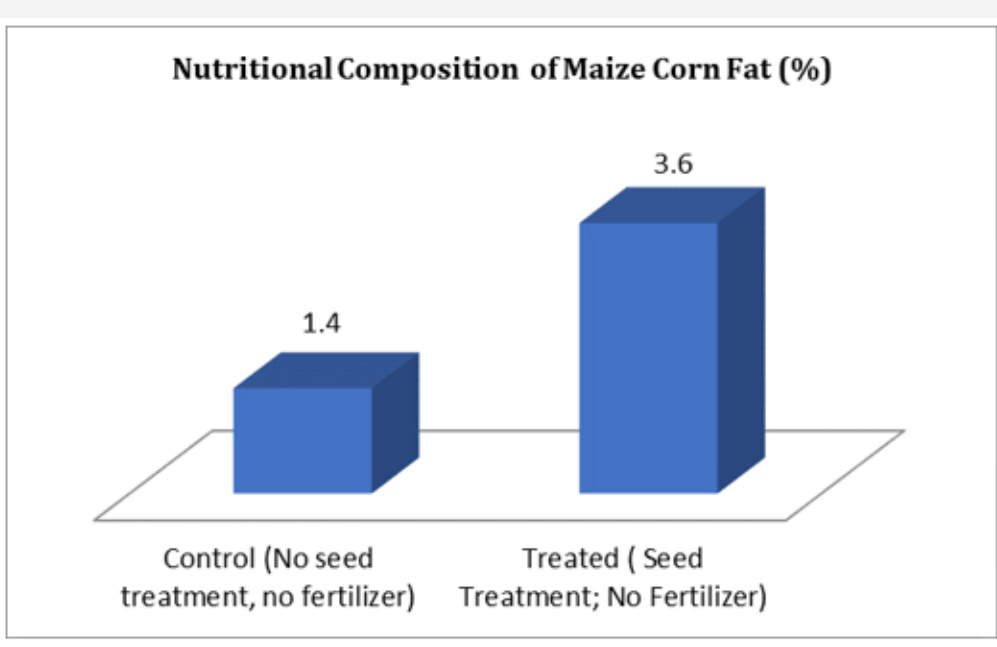

Figure 4: Nutritional Composition of Maize Corn [11].

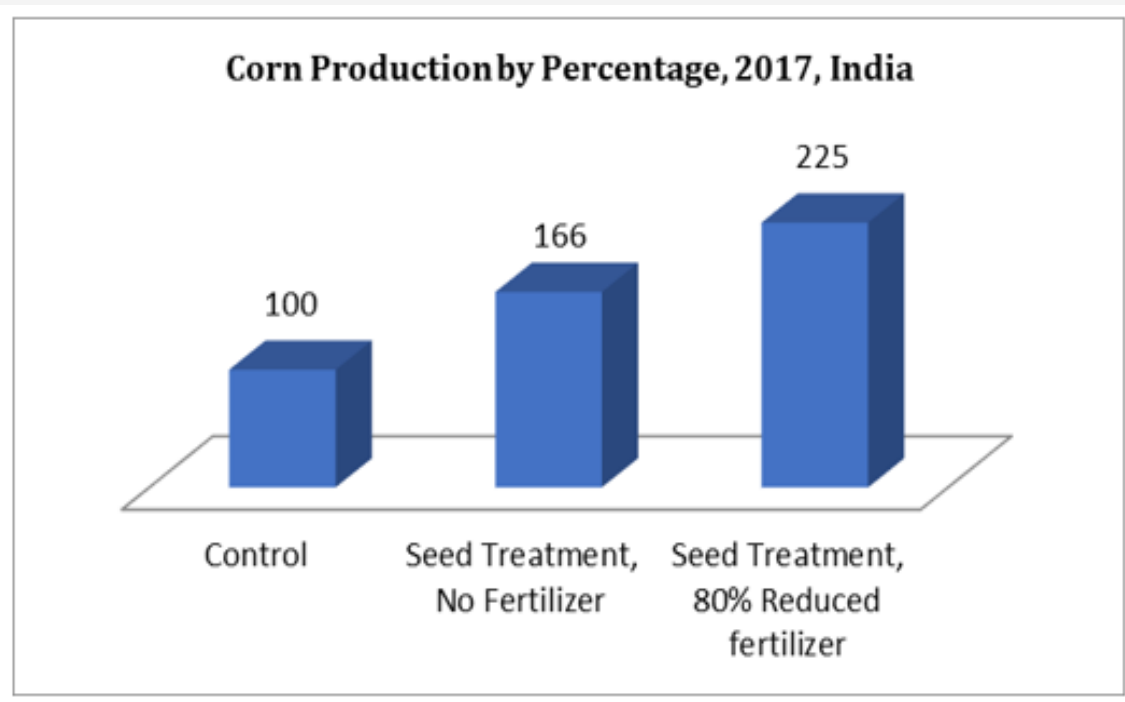

Figure 5: Percentage Corn production in 2017 by an Independent Evaluation e-Kutir Rural Management Services. 
According to the report by International Institute of Tropical Agriculture (IITA) on the Support to Agricultural Research for Development of Strategic Crops in Africa (2017), in sub-Saharan Africa, maize is the most widely grown crop and is a staple food for an estimated $50 \%$ of the population and 46 out of 53 countries grow and largely depend on maize as a major source of food. Despite the high dependence on the crop, growth in maize yields in much of sub-Saharan Africa (SSA) has failed to keep pace with other developing and more developed regions of the world. A common explanation for poor growth is low level use of fertilizer and lack of adoption of improved seed variety.
This initiative will be addressing these perennial challenges using the model system called Regional Economics Agricultural and Community Help (REACH). The program allows for interaction with farmers and selects them for the REACH program. It is through this mission that the program aims to empower local farmers in groups to become the base for a farm to table solution that will benefit each level of the value chain. The program has the potential to increase yield by over $200 \%$ while at the same time reducing cost of production by over $55 \%$ and thus increase the profit margin and thus enable farmers to pursue farming as a business as shown in Figure 6.

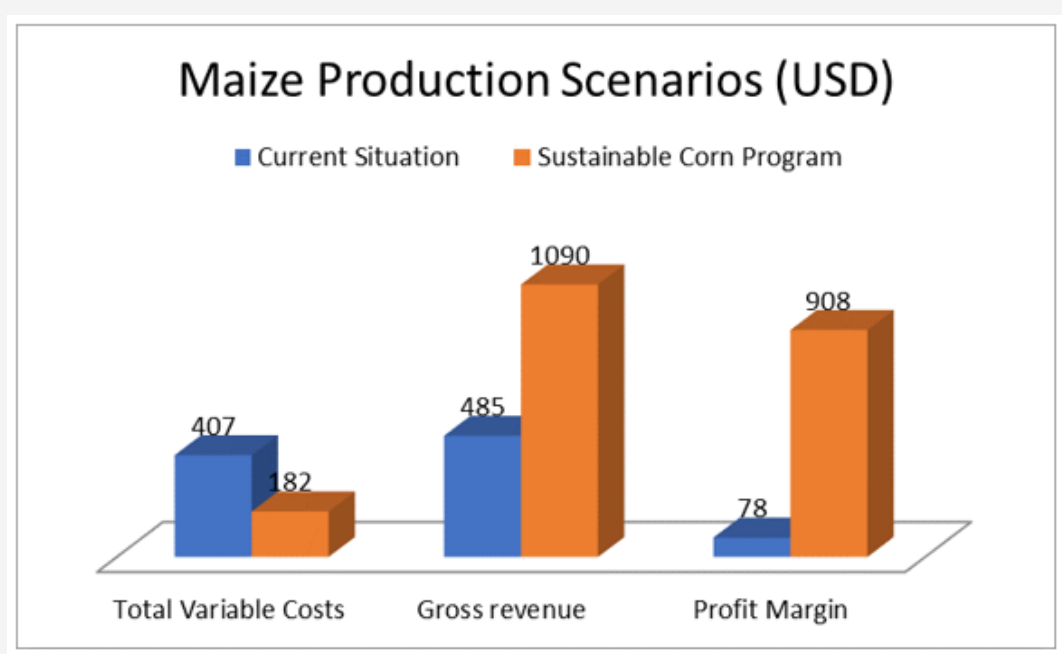

Figure 6: Comparison of current situation and sustainable corn program.

\section{Materials and Methods}

\section{Procedures}

A maize Demonstration Farm was established at Narayankhed, in the Sangareddy District of Telangana State of India from July to October 2018. Two paid host farmers were actively involved in all the operations that were carried out in the farm.

The demonstration Farm was established to demonstrate to farmers the best technologies locally available in maize production, provide a learning platform for farmers to apply these technologies on their farms, interact with farmers and select them for the REACH program. The model system used is called Regional Economics Agricultural and Community Help (REACH) program. It is through this mission that goals to empower local farmers in groups becomes the base for a farm-to-table solution that will benefit each level of the value chain as it currently exists as the core of the sustainable business proposition for Salvation Farming Solutions.

The demonstration farm was further used to test the Sustainable Corn Program nature-based seed, soil and fertilizer treatment solutions marketed by Salvation Farming Solutions in the local field location, the development and productivity of the livestock and poultry sectors could also depend on the maize value chain since maize is a major component of poultry and livestock feed. This is a report on a successful maize Demonstration Farm which was established at Narayankhed, in the Sangareddy District of Telangana State of India as part of the "Sustainable Agriculture Trials - Maize" project.

\section{Materials}

The treatments available included:

- Soil Detox treatment supplied as a liquid concentrate that is mixed with water and sprayed on the field to be treated.

- $\quad$ Seed Soak Treatment supplied as a powder mix to be added with a liquid catalyst to a bucket of water. The seeds are soaked in 5-gallon bucket overnight.

- $\quad$ Seed Powder Treatment is a dry mix put in bag with seeds with a liquid catalyst and shaken to cover the corn kernels with powder.

- Fertilizer Treatment is a powder mix that is mixed into fertilizer to improve fertilizer and can reduce fertilizer materials used by $80 \%$ or more.

- $\quad$ Natural Pesticide is a multipart liquid mix diluted with water that applied as a spray only if pests appear on the crop.

Plot was planted in sandy red soil with no irrigation used for crop watering, expected monsoon rains were the only source of water for maize crop. The only heavy rain was 2 days before planting and 10 days after planting otherwise only a few short showers; crops faced extreme drought conditions. 


\section{The Field Trial Process}

The Farm, under the overall coordination of Saral Jeevan India Foundation staff. The establishment of the Demonstration Farm was part of a Trainer of Trainers for Farmer Field Schools. The selected farmers were allowed to use their regular seeds and their practices for planting but just before the sowing a few extra activities were carried out during the pilot process:

- $\quad$ After tilling Soil Detox solution was sprayed in the selected treatment area.

- Seeds were treated with the recommended solutions:

- Seeds in one part were soaked in the recommended solution for 24 hours before the sowing;

- Seeds in the second part were applied with powder coating.

- $\quad$ Application of fertilizer advised and made sure that at least $50 \%$ less was applied in the treatment area

- $\quad$ No pesticides and herbicides were used

The participating farmers were convinced through the activities carried out on the Demonstration Farm that by using the appropriate technologies and techniques acquired they could significantly increase maize productivity on their individual farms. This would increase their incomes and improve their economic and social well-being. Overall, the farmers were very appreciative of the training given to them by the project.

\section{Land clearing}

The schedule of the various activities carried out on the farm between June and November 2018. Land clearing, ploughing, field inspection, spraying of soil treatment solution and soaking of the seed for 24 hours before sowing was carried out between June and July 2018. First fertilizer application and first weeding were done in September 2018. Harvesting and data analysis was done in October and November 2018.

\section{Land preparation and planting}

Land clearing using manual labor was done and the weeds were collected, and field lay out was done.

The field was ploughed in the presence of the selected farmers for joint learning. Planting was done on July 15, 2018 at the period when groundwater and soil temperature were suitable. Planting was scheduled such that the heat and water sensitive growth stage of maize (i.e. the flowering stage) did not coincide with the period of drought.

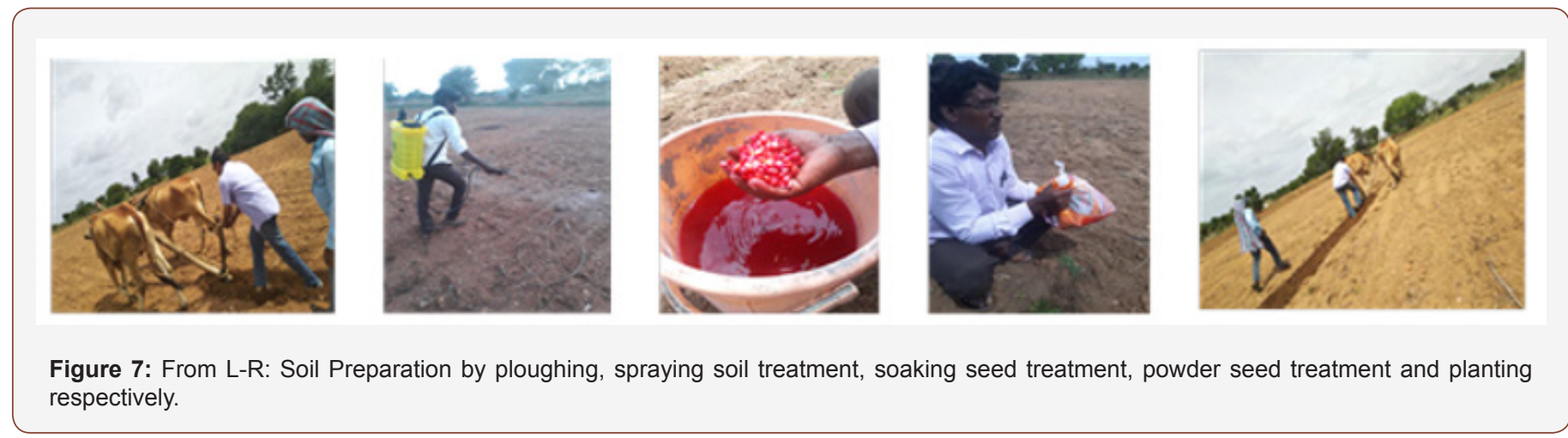

Planting depth of maize varied from 5 to $10 \mathrm{~cm}$, depending on the soil type and planting date. As a rule, planting should be shallower in heavier soils than in sandy soils. Planting was done by the participating local farmers as shown in Figure 7 who were selected for joint learning so that they would apply the technologies on their respective farms.

\section{Weed Control}

Successful cultivation of maize depends largely on effective weed control (Figure 8). Weed control during the first six to eight weeks after planting is crucial, because weeds compete vigorously with the crop for nutrients, water and light during this period. The annual yield loss in maize because of weed problems is estimated to be approximately $10 \%$. The presence of weeds during harvesting may slow the process, contaminate grain with seeds, transmit odors to grain to reduce grain quality or may incur additional cost for the removal of seeds. Weeds were removed mechanically, by hoe or by hand. No inorganic weedicide (herbicide) was applied throughout the study.

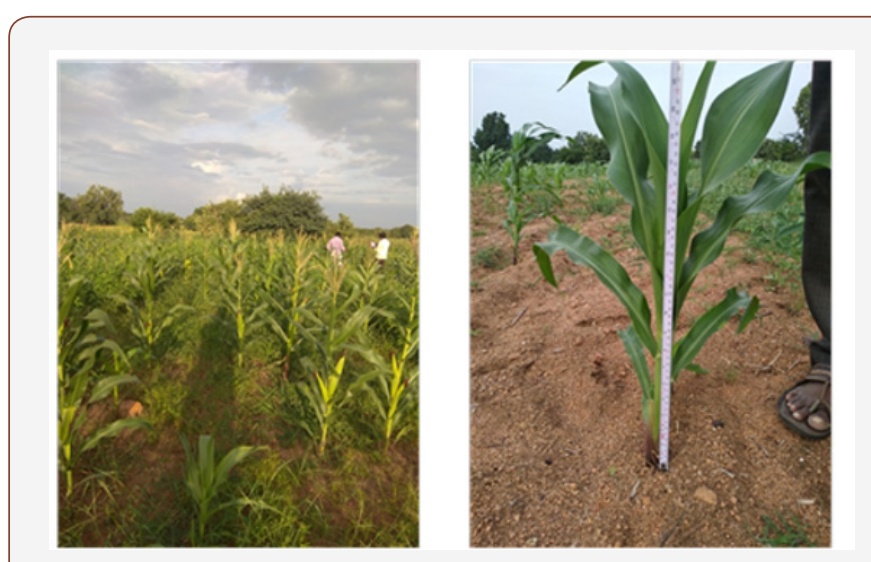

Figure 8: Before and after weeding of the planted maize field.

\section{Results}

After 60 days the treated crops caught up on growth and significantly increased production. Control maize was ready for harvest at week 14 whereas treated plants were ready for harvest at week 10 (one month earlier). 
Compared by weights to control maize; Powder treated maize increased crop production by $290 \%$ whereas Seed Soak treated maize increased crop production by $200 \%$.

In terms of increase in maize plant biomass by volumes compared to control; Powder treated maize increased biomass crop production by $210 \%(\mathrm{p}<0.0001)$ while Seed Soak treated maize increased biomass crop production by $142 \%(\mathrm{p}<0.001)$. This biomass increase indicates higher carbon sequestration from carbon farming and potential applications for mulch, compost and green fodder or other uses.

Compared to control; Powder treated maize roots were $214 \%$ $(\mathrm{p}<0.0001)$ larger than controls at mid-crop measurement; Soak treated maize roots were $228 \%(\mathrm{p}<0.0001)$ larger than controls at mid-crop measurement. These larger root measurements indicate the potential for higher plant resiliency to drought, plant strength and higher biomass growth, and the potential for increased nutrient uptake from the soil.

The treated soil appeared darker, indicating greater soil microbial life and greater retention of water. Farmers also noticed treated maize leaves were noticeably brighter and larger than control group.

When looking at cost savings from Field Trial products; there was $50 \%$ fertilizer use reduction and no herbicide or pesticide was used. This translates up to 5 times the actual costs of production. Conversely for the $50 \%$ fertilizer use and no herbicide or pesticide used translates to $80 \%$ saving in farm inputs. Control group was treated with $100 \%$ fertilizer.

No pests or diseases were found on treated corn groups (Powder and Soak); beneficial red beetles also were found on treated corn and not on control corn. Control group was infested with pests and affected by maize mycotoxin.

Harvested treated corn tasted softer and "tastier" in flavor compared to Control corn.

Soaked and Powder treated maize plants were ready for harvest $25 \%$ earlier (week 10-11 versus week 14) than Control, indicating the potential for additional second or third cropping production in relevant regions along with better opportunities for market pricing.

Good agricultural practices were carried out on the farm with the participating farmers resulting in maximum crop growth and development.

\section{Root Checking and Measurements During the Crop Growth}

Regular crop growth measurement was done by the field teams. Every week crop measurement and pictures were sent to the HQ and to the research teams with the details of the of the height of the sample randomly selected plants, number of leaves on plants, width and thickness of the plant, and growth roots of the plants were compared as shown in Figure 9.

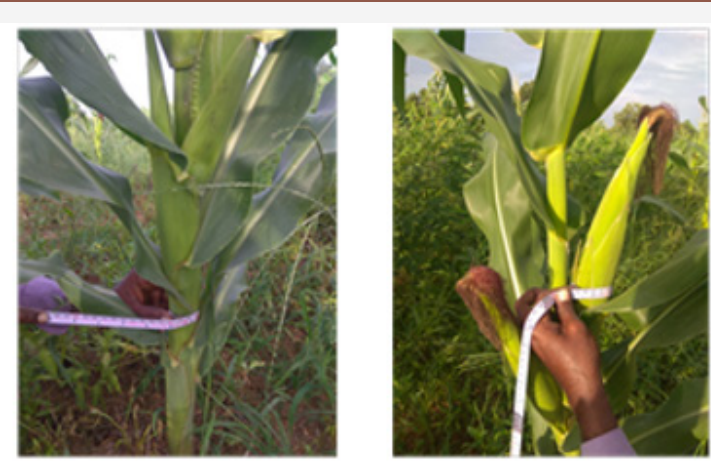

Figure 9: Measuring stalk height, root size, stalk width and cob dimensions respectively.

- Height of the sample randomly selected plants

- $\quad$ Number of leaves on plants

- Width and thickness of the plant

- At one point the growth of the roots of the plant also compared

\section{Discussion}

These increases in nutritional density coupled with more than double growth rates using $100 \%$ natural and organic solutions can be quite competitive compared to present commercial farm conditions. Benefits of this system can reduce fertilizer use up to $80 \%$. Overall costs for this increased production may be up to $50 \%$ savings for the farmers with doubling crop production with potential to quadruple income. This economic value will be further driven by demand for this better tasting, healthier corn. We have developed a total plan for this platform from seed to finished product which will be easy to sell into the market with high penetration based on regional government, private sector and development partners' support.

\section{Unlocking what has been collected in soil}

Recent studies demonstrating more than double growth in healthy corn cobs produced and $100 \%$ pest control done with planting in soil tremendously affected by climate change and chemical abuse is leading to a new theory based in soil remediation science that it may be possible to rejuvenate soil to improve productivity using nature-based products. Additionally, downstream, field effluents from treated fields and soils are being seen positively as these streams are becoming less polluted and 
fisheries are recovering in oceanic areas due to increased water quality and nutrient availability affecting plankton abundance for fish fry in these coastal areas to eat and thrive culminating in increased more sustainable fisheries harvests.

The field that was used for the trial was later discovered to be a tract of unproductive land that locals were unwilling to grow maize on. However, through the efforts of the participating farmers and the Agriculture Extension Officer, a healthy crop with appreciable yield was obtained.

The key lessons learned were that farming in dry lands was very challenging especially erratic rainfall during crucial crop growth stages such as sprouting and cob development. The lack of rainfall can result in total crop failure or losses to farmers.

The Soaked seeds were able to withstand the drought well and sprouted well in time, but Powder coated seeds withstood the drought very well and gave good yield.

\section{Conclusion}

Both the Powder and Soak Treatments increased productivity significantly (Powder 290\%, Soak 200\%) compared to the Control Group under drought conditions and significantly increased stalk and root (silage production) size (Powder 210\%, Soak 142\%). Secondarily, the improved flavor, pest and disease resistance provided by the treatments, even without pesticides will prove of value for future farmer and consumer adoptions of this innovative and novel treatment program.

Given the significant farmer cost savings and improved production output with this program it is recommended that Market Demonstrations be pursued to make these solutions more available for smallholder farmers as climate resilient options for improved food security and economic development for the sector.

Overall, the farmers were very appreciative of the training given to them by the project. They, however, emphasized the need for the development of sustainable maize postharvest management system in Telangana with focus on efficient storage and marketing to enable maize farmers obtain good prices for their produce.

As we make progress towards achieving the United Nations Sustainable Development Goals focus needs to be on game changing processes rather than business as usual with government support needed to be front and center for these new ways forward.

\section{Foods and Nutrition}

It is clear that we are what we eat and that our health is directly related to our nutrition [11]. We believe that consumption of the Salvation Farming Solutions treated corn will promote better community health and well-being just by the nature of consumption. Medical studies will be getting underway soon in order to fully maximize and understand the health benefits of these technologically improved plants and seeds.

\section{Acknowledgement}

Gail Work, One Earth Ventures and Harvest Laborers International for being friends and concept supporters.

\section{Conflict of Interest}

No conflict of interest.

\section{References}

1. Action Aid (2015) Contract farming and out-grower schemes. Appropriate development models to tackle poverty and hunger? Policy discussion paper, pp. 1-12.

2. Carroll T, A Stern, D Zook, R Funes, A Rastegar, et al. (2012) Catalyzing Smallholder Agricultural Finance. Dalberg Global Development Advisors, p. 48.

3. Etyang TB, Okello JJ, Okoth PF, Zingore S, Waswa BS, et al. (2014) Exploring the relevance of the agro-input dealers' suitability for disseminating and communicating soil fertility management practices. The case of Siaya and Trans Nzoia Counties; Agricultural Information Worldwide 6.

4. Thompson GD, Dutton R, Sparks TC (2000) Spinosad - case study: an example from a natural products discovery programme. Pest Management Science 56(8): 696-702.

5. Liambila NR, Wesonga JM, Ngamau CN, Waudo W (2018) Why does Lantana camara L. (Verbenaceae) tick as a new source of pesticide? A review of its essential oil's bioactive properties. Presented at the $18^{\text {th }}$ Horticultural Association of Kenya workshop on Sustainable Horticultural Production in the Tropics, pp. 26-30.

6. Miller C, L Jones (2010) Agricultural value chain finance. Tools and lessons, Food and agriculture organization of the United nations (FAO), pp. 1-195.

7. Meyer RL (2015) Financing agriculture and rural areas in sub-Saharan Africa. Progress, challenges and the way forward, IIED Working Papers. IIED, London.

8. Sonnenschein L (2017) If we are what we Eat, how have Decreases in Nutritional Densities of Food Affected Health? Biomed J Sci \& Tech Res 1(2): $1-2$.

9. Sonnenschein L (2013) Understanding Cellular Metabolism: Nutrition, Health and Beauty. Amazon.com.

10. De Busk RM ,Fogarty CP, Ordovas JM , Kornman KS (2005) Nutritional genomics in practice: where do we begin? J Am Diet Assoc 105(4): 589598.

11. (2017) Support to Agricultural Research for Development of Strategic Crops in Africa, SARD-SC Business Unusual Approach to ensure Food Security and Combat Poverty. IITA Ibadan, Nigeria. 86 pp. 